\title{
Tratamento superficial de agregados graúdos reciclados para produção de concretos
}

\section{Surface treatment in recycled coarse aggregates for concrete production}

\author{
Tratamiento superficial en piedras recicladas para producción \\ de hormigón
}

\section{Traitement de surface dans de granulats recyclés grossiers pour la production de béton}

Marina Guerra Fontes

Silva

marinaguerraf@outlook.com Engenheira da Mobilidade Universidade Federal de Itajubá (Unifei) - Campus Itabira (MG)

Marconi Oliveira de Almeida marconi.almeida@unifei. edu.br

Universidade Federal de Itajubá (Unifei) - Campus Itabira (MG)

Sérgio Pacífico Soncim sergiops@unifei.edu.br Universidade Federal de Itajubá (Unifei) - Campus Itabira (MG)

\section{Carlos Augusto Souza Oliveira}

carlosoliveira@unifei.edu.br Universidade Federal de Itajubá (Unifei) - Campus Itabira (MG)

\section{Resumo}

A destinação incorreta dos resíduos da construção civil, como agregado graúdo reciclado, acarreta danos ao meio ambiente. O reuso desse material é fundamental, entretanto a taxa de absorção desses agregados é maior quando comparados aos agregados naturais, sendo um dificultador. O objetivo deste trabalho foi reduzir essa taxa de absorção promovendo um tratamento superficial, com pasta de cimento, e analisar a influência no agregado tratado, bem como em concretos confeccionados com ele. O agregado graúdo reciclado passou por dois tratamentos, nos quais foi promovido um banho utilizando pasta de cimento nas proporções de 1:10 e de 2:10, sendo respectivamente 1 parte de cimento no primeiro e 2 partes no segundo. Na caracterização do agregado tratado, constatou-se um aumento da massa unitária, justificado pela camada externa formada ao redor do grão. Quanto à absorção, houve uma redução de $15,83 \%$ e de $11,28 \%$, respectivamente, para as proporções de $1: 10$ e de 2:10, quando comparados ao agregado graúdo reciclado sem tratamento. Foram confeccionados três tipos de concreto, um com agregado graúdo reciclado sem tratamento e outros dois com tratamentos de 1:10 e 2:10. No estado endurecido, foram realizados testes de resistência à compressão simples, resistência à tração por compressão diametral e velocidade de pulso de ultrassom. Na resistência à compressão aos 28 dias, o concreto com o tratamento na proporção de $1: 10$ obteve aumento de $21,44 \%$, enquanto o concreto com o tratamento na proporção de 2:10 obteve aumento de $36,31 \%$ nessa propriedade. Já na resistência a tração aos 28 dias, aumentos de $10,38 \%$ e de $26,06 \%$, respectivamente, foram encontrados.

Palavras-chave: Agregado reciclado. Tratamento superficial. Concreto.

\footnotetext{
Abstract

The incorrect disposal of construction waste, such as recycled coarse aggregate, causes damage to the environment. The reuse of this material is essential; however, the absorption rate of these aggregates is higher when compared to natural aggregates, being a hindrance. The objective of this work was to reduce this absorption rate by promoting a superficial treatment, with cement paste, and to analyze the influence on the treated aggregate, as well as, on concretes made with it. The recycled coarse aggregate underwent two treatments, where a bath was promoted using cement paste in the proportions of $1: 10$ and 2:10, with 1 part of cement in the first and 2 parts in the second, respectively. In the characterization of the treated aggregate, an increase in unit mass was found, justified by the outer layer formed around the grain. As for absorption, there was a reduction of $15.83 \%$ and $11.28 \%$, respectively, for the proportions of $1: 10$ and $2: 10$, when compared to the coarse aggregate
} 
recycled without treatment. Three types of concrete were made, one with coarse aggregate recycled without treatment, and the other two with 1:10 and 2:10 treatments. In the hardened state, tests were performed for simple compression strength, tensile strength by diametrical compression and ultrasound pulse speed. In the compressive strength at 28 days, the concrete with the treatment - $1: 10$ - obtained an increase of $21.44 \%$, while the concrete with the treatment - $2: 10$ - obtained an increase of $36.31 \%$ in this property. As for tensile strength at 28 days, increases of $10.38 \%$ and $26.06 \%$ were found.

Keywords: Recycled aggregate. Surface treatment. Concrete.

\section{Resumen}

El destino incorrecto de los residuos de la construcción civil, como piedras recicladas, provoca daños al medio ambiente. La reutilización de este material es fundamental. Sin embargo, la tasa de absorción de estos residuos es mayor cuando comparados a los residuos naturales, siendo un dificultador. El objetivo de este trabajo fue reducir esta tasa de absorción fomentando un tratamiento superficial, con pasta de cemento, y analizar la influencia en la piedra tratada, así como en hormigones hechos con ella. La piedra reciclada pasó por dos tratamientos, donde fue promovido un baño utilizando pasta de cemento en las proporciones de 1:10 y de 2:10, siendo respectivamente 1 parte de cemento en el primer baño y 2 partes en el segundo. En la caracterización de la piedra tratada, se percibió un aumento de la masa unitaria, justificado por la camada externa formada alrededor del grano. Cuanto a la absorción, hubo una reducción de $15,83 \%$ y de $11,28 \%$, respectivamente, para las proporciones de 1:10 y de 2:10, cuando comparados a la piedra reciclada sin tratamiento. Fueron hechos tres tipos de hormigón, siendo uno con piedra reciclada sin tratamiento, y otros dos con tratamientos de 1:10 y 2:10. En el estado endurecido, fueron realizados testes de resistencia a la compresión simple, resistencia a la tracción por compresión diametral y velocidad de pulso de ultrasonido. En la resistencia a la compresión a los 28 días, el hormigón con tratamiento - 2:10 - obtuvo aumento de 36,31\% en esta propiedad. Ya en la resistencia a la tracción a los 28 días, aumentos de 10,38\% y de 26,06\% fueron encontrados.

Palabras-clave: Piedra reciclada. Tratamiento superficial. Hormigón.

\section{Résumé}

L'élimination incorrecte des déchets de la construction, tels que les granulats recyclés grossiers, cause des dommages à l'environnement. La réutilisation de ce matériau est fondamentale. Portant, le taux d'absorption de ces granulats est plus élevé par rapport aux agrégats naturels. C'est un mal dont il faut vaincre. L'objectif de ce travail a été :1) de réduire ce taux d'absorption, au même temps qu'on développe un traitement de surface, avec du coulis du ciment et 2) d'analyser l'influence sur le granulat traité et sur le béton qui a été fait avec du granulat. Le granulat recyclé grossier a été subi à deux traitements, dans lesquels un bain a été promu en utilisant du colis du ciment dans les proportions de $1: 10$ et $2: 10$, respectivement 1 partie de ciment dans la première et 2 parties dans la seconde. Dans la caractérisation de l'agrégat traité, il y a eu une augmentation de la masse unitaire, justifiée par la couche extérieure formée autour du grain. En ce qui concerne l'absorption, il y a eu une réduction de $15,83 \%$ et de $11,28 \%$, respectivement, pour les proportions de $1: 10$ et $2: 10$, par rapport au granulat recyclé grossier sans traitement. Trois types de béton ont été fabriqués : l'un avec du granulat recyclé grossier sans traitement, et deux autres avec des traitements de $1: 10$ et $2: 10$. À l'état durci, on a exécuté des tests de la résistance à la compression simple et à la traction par compression diamétrale, bien comme des tests de vitesse des ultrasons. Après 28 jours de la résistance à compression, le béton avec le traitement - $1: 10$ - a obtenu une augmentation de 21,44\%, tandis que le béton avec le traitement - $2: 10$ - a obtenu une augmentation de $36,31 \%$. Après 28 jours, la résistance à la traction, a présenté des augmentations de $10,38 \%$ et $26,06 \%$.

Mots-clés: Granulat Recyclé. Traitement superficiel . Béton. 


\section{Introdução}

O desenvolvimento da humanidade consumiu grande quantidade das matérias-primas do planeta para garantir que a população mundial tivesse um conforto cada vez maior. A indústria da construção civil é a maior consumidora de recursos naturais do planeta, produzindo grande quantidade de resíduos sólidos, os resíduos de construção e demolição $(R C D)$, gerando preocupação em vários países, uma vez que estão intimamente relacionados a questões sociais, ambientais e financeiras (MOTTA, 2005; DAMINELI, 2007).

Os resíduos da construção civil são provenientes de diversas origens, como a baixa qualidade de bens e serviços, causando perdas de materiais, que geram entulhos, e aumento do volume de resíduo gerado. Esses resíduos são somados aos de demolição, causados pelo crescimento econômico e populacional das cidades e pela manutenção, recuperação e reforma das estruturas (LEITE, 2001; CARRIJO, 2005).

Os resíduos normalmente são compostos por sobra de argamassa, tijolo, concreto, cerâmica, rochas e madeira, e são considerados, em sua maioria, inertes. A reciclagem do RCD traz benefícios econômicos e ambientais, pois voltam como substituição a novos agregados que seriam retirados do meio ambiente (COSTA et al., 2007).

Os RCD podem ser utilizados como agregados reciclados na produção de concreto, camadas de base e sub-base para pavimentação, fabricação de argamassas de assentamento e revestimento, fabricação de pré-moldados, camadas drenantes, entre outros. Os RCD possuem algumas propriedades diferentes quando comparados aos agregados naturais, como absorção de água, massa específica, módulo de elasticidade e fluência (GONÇALVES, 2001; BRASILEIRO, 2013).

O concreto com agregado reciclado possui características diferentes dos concretos convencionais, a qual está relacionada com a qualidade e o tipo do RCD. Resistência mecânica, absorção de água, porosidade, permeabilidade, retração por secagem, módulo de elasticidade, fluência e massa específica são algumas das propriedades que podem ser alteradas com o uso do agregado reciclado (LIMA, 1999).

MOTTA (2005, apud UTS, 1999) afirma que as diferenças entre os agregados naturais e os reciclados são: formato e textura superficial do grão, que, no agregado reciclado, é mais irregular; a densidade, que, por ser mais poroso, tende a ser menor nos agregados reciclados; e a absorção de água, que é a característica com maior diferença entre os dois agregados quando se refere à propriedade física.

As propriedades influenciadas pela porosidade e absorção de água dos agregados são a aderência entre os agregados e a pasta de cimento, a resistência à abrasão, a massa específica e a estabilidade química da mistura (ATHAYDE, 2018).

Os agregados reciclados possuem taxa de absorção de água maior que as dos agregados convencionais. A porosidade dos agregados está relacionada à pasta endurecida e à presença de cerâmica vermelha. $A$ absorção de água das partículas cimentícias - na fase cinza é de até 15\%, nas partículas de cerâmica vermelha e, na fase vermelha, é de até $24 \%$ (SANTOS, 2016).

Apesar das diferentes características do RCD quando comparado aos agregados convencionais, em função da origem do mesmo, Lima (1999) ainda afirma que, tomados os devidos cuidados com a produção do agregado e do novo concreto (como escolha do resíduo, controle de qualidade, adoção de procedimentos corretos de aplicação), pode ser utilizado em inúmeras obras da construção civil, até mesmo as de competência estrutural.

Partindo dessa premissa, a fim de proporcionar melhorias nas propriedades físicas e mecânicas dos RCD e, por consequência, nos concretos confeccionados com eles, este trabalho utilizou a técnica de tratamento superficial feita com pasta de cimento. Este estudo teve como objetivo avaliar as transformações ocorridas no agregado graúdo reciclado após tratamento superficial com pasta de cimento, bem como avaliar as características físicas dos concretos confeccionados com esse agregado tratado.

Essa técnica foi apresentada no estudo de Almeida, Santos e Sousa (2018), em que conseguiram reduzir a absorção dos agregados reciclados em aproximadamente $35 \%$ ao realizar tratamento superficial com pasta 
de cimento nos agregados reciclados. Com o tratamento, observou-se, também, o aumento da resistência dos blocos de concreto produzidos com o agregado graúdo com tratamento superficial.

O tratamento superficial do agregado reciclado visa melhorar as características de absorção do mesmo, melhorando, por consequência, as características do concreto, tanto no estado fresco, facilitando o processo de mistura, como no estado endurecido, alterando as propriedades físicas.

Diante do exposto, esta pesquisa tem como relevância contribuir para o aprimoramento do comportamento físico e mecânico dos agregados reciclados, aumentando a qualidade do produto acabado. Essa melhoria de qualidade pode permitir uma maior versatilidade de uso do agregado reciclado, seja de forma isolada, seja em misturas cimentícias, tornando-o uma opção viável para diversas situações.

\section{Metodologia}

Nesta pesquisa, o tratamento superficial do agregado graúdo reciclado foi realizado na proporção de 1:10, sendo uma parte de cimento e 10 partes de água, e também foi testado na proporção de 2:10, sendo agora duas partes de cimento para 10 partes de água.

Como dito anteriormente, o tratamento utilizado teve como referência o trabalho realizado por Almeida, Santos e Sousa, (2018) em agregados graúdos reciclados, utilizados na confecção de blocos de concreto para alvenaria estrutural. Naquela ocasião, os agregados reciclados eram de origem cimentícia, sendo estritamente resíduo de concreto e argamassa.

Como o material utilizado nesta pesquisa foi um resíduo com características heterogêneas, como observado na Fig. 1, foi necessário um trabalho de pré-teste a fim de ajustar a melhor forma de promover a absorção, potencializando o processo de tratamento superficial.

Figura 1 - Composição do RCD utilizado

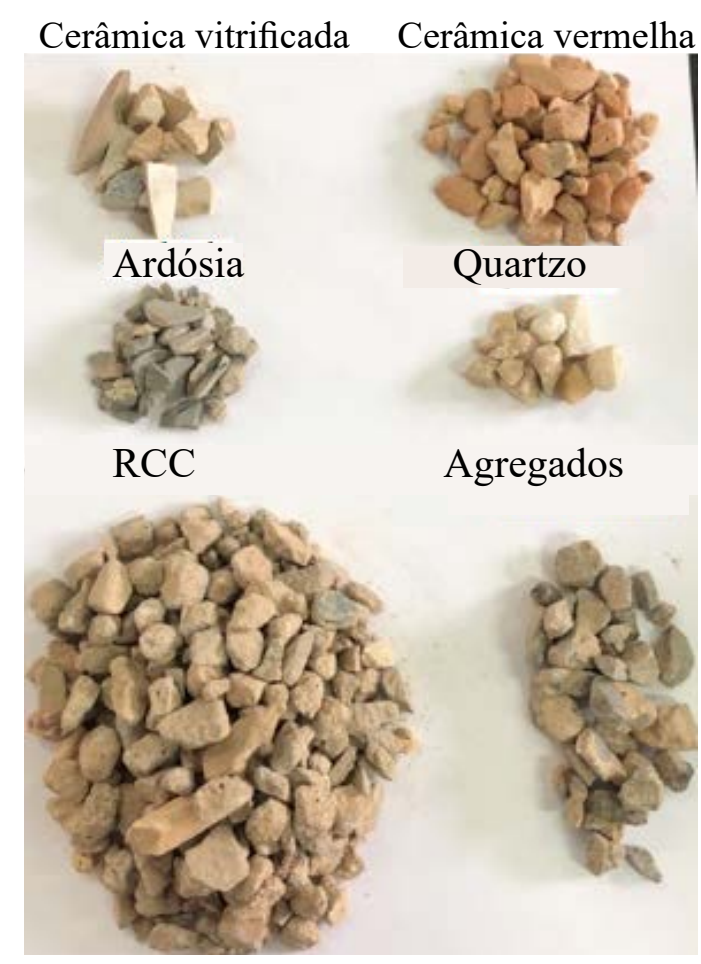

Fonte: Elaborado pelos autores, 2020.

A primeira etapa consistiu em realizar a mistura da água e cimento em um recipiente. Em seguida, o agregado graúdo reciclado foi colocado na betoneira com a mistura de água e cimento e revolvido por 5 
minutos. Após esse período, foi disposto em bandejas e revirado a cada hora, sendo que esse processo não promoveu melhoras na absorção após 7 dias de cura.

Em uma nova etapa, o material agregado graúdo reciclado e a pasta de cimento foram misturados e revolvidos na betoneira a cada meia hora, por um período de seis horas. O material era revolvido nesse intervalo de tempo para que não aderisse nas paredes da betoneira, e de forma a permitir um maior tempo de absorção a ser feito pelo agregado. A ideia de um maior tempo de contato entre pasta e agregado era para permitir o preenchimento dos poros deste último e, consequentemente, promover uma melhoria da taxa de absorção do agregado graúdo reciclado.

Feita essa etapa, o material foi disposto em bandejas e, no dia seguinte, ainda úmido, colocado para terminar a secagem em lona plástica (Fig. 2). O processo de cura seguiu sendo de 7 dias para o início de realização dos testes de caracterização do material tratado, bem como do agregado graúdo reciclado sem tratamento. Decorridos sete dias, assim como no primeiro teste, foi realizado novo ensaio de absorção de água, comprovando que o novo procedimento de tratamento superficial com pasta de cimento sofreu melhorias consideráveis quando comparado com o primeiro.

Figura 2 - Secagem e cura do agregado graúdo reciclado após tratamento com pasta de cimento

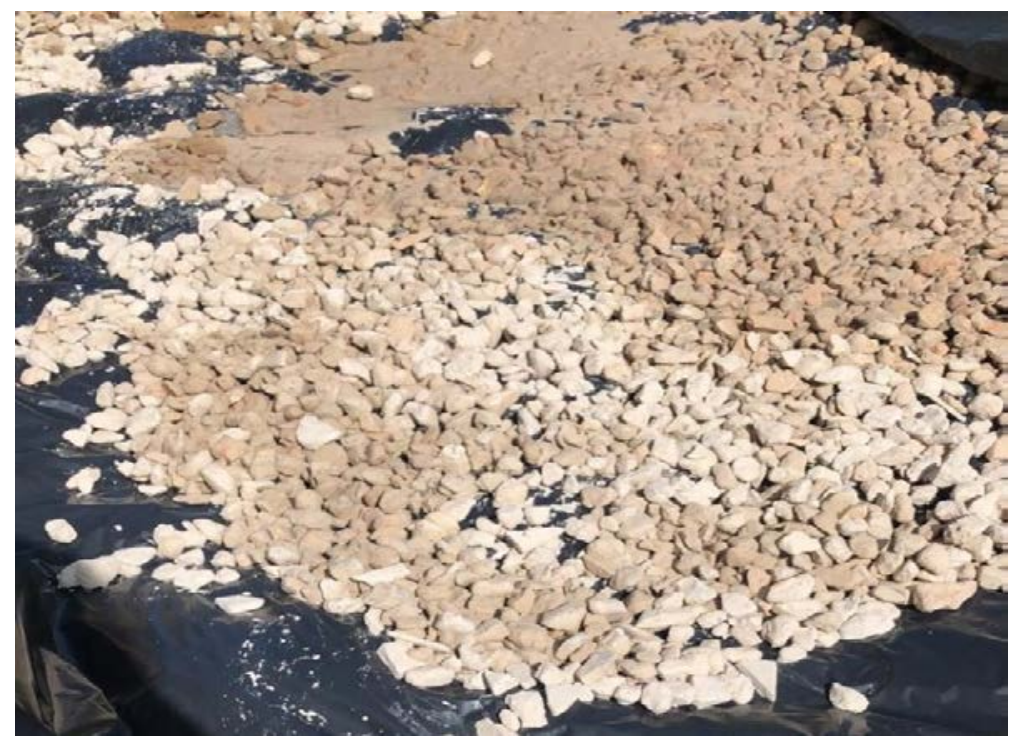

Fonte: Elaborado pelos autores, 2020.

Definidos os procedimentos para o tratamento superficial a ser realizado no agregado graúdo reciclado, passou-se, então, para a definição do projeto de estudo. Foram analisadas as características físicas do agregado reciclado, com e sem tratamento, e as características dos concretos confeccionados com esses materiais.

O projeto proposto para os concretos confeccionados com o agregado graúdo reciclado, com e sem tratamento, é apresentado na Fig. 3. Cabe ressaltar que, para as análises dos concretos, foram estudados 3 traços utilizando $100 \%$ de agregado graúdo reciclado, sendo um sem tratamento superficial, outro com tratamento superficial com pasta de cimento na proporção de 1:10 e o último com o mesmo tratamento superficial na proporção de 2:10. 
Figura 3- Projeto experimental definido para o estudo

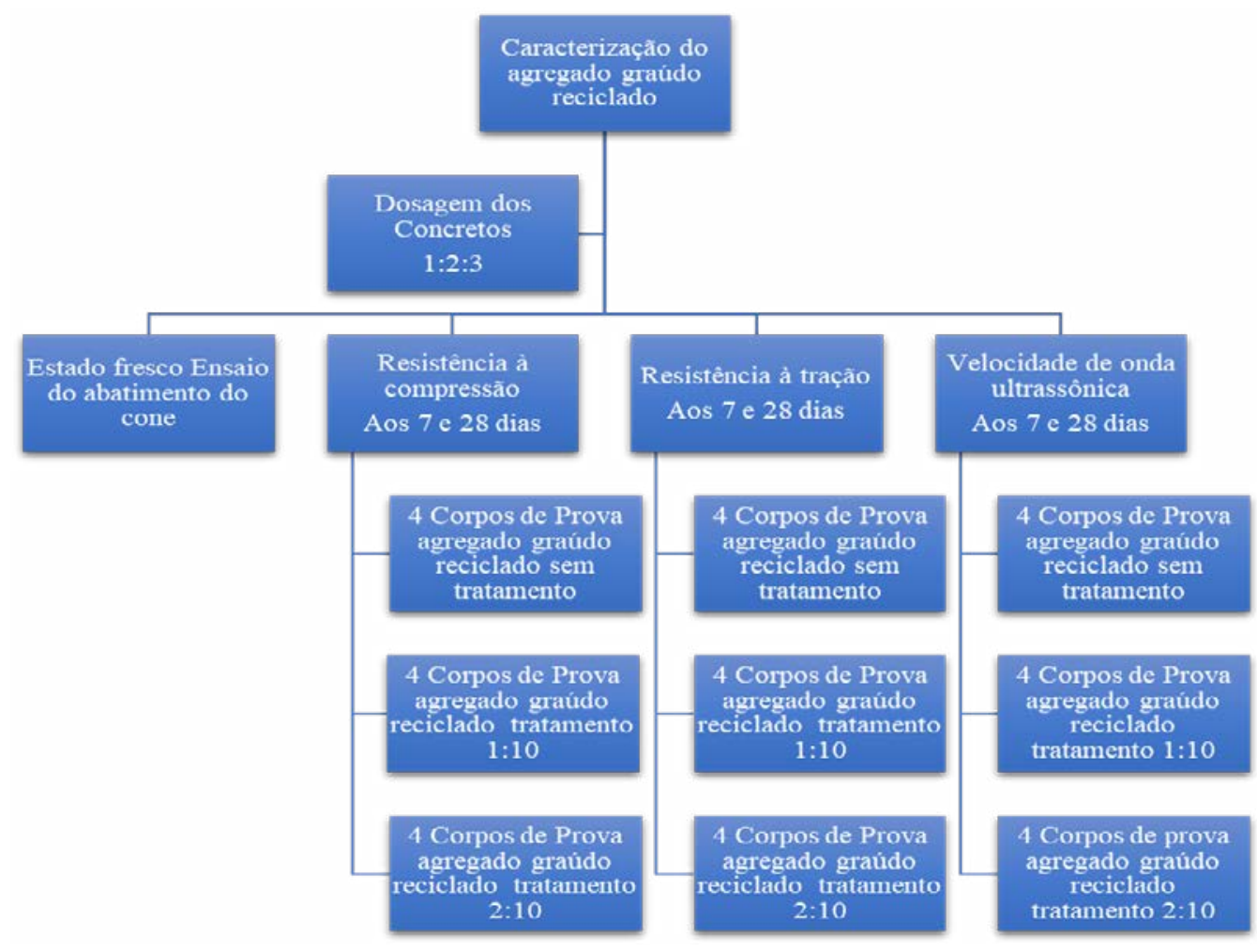

Fonte: Elaborado pelos autores, 2020.

Como apresentado na Fig. 3, trabalhou-se com um traço empírico comumente empregado em obras com concretos dosados no local (traço 1:2:3), utilizados, inclusive, na concretagem de peças estruturais. Os ensaios de caracterização dos agregados graúdos reciclados, sem e com tratamento, foram definidos da seguinte forma:

- Composição do agregado graúdo reciclado, utilizando análise visual e seleção de grupos;

- Análise granulométrica, $D_{\text {máx }}$ e MF (módulo de finura), conforme ABNT NBR NM 248/2003;

- Massa específica e absorção de água, conforme ABNT NBR NM 53/2009;

- Massa unitária, conforme ABNT NBR NM 45/2006.

Os materiais convencionais utilizados na confecção do concreto foram: cimento Portland de alta resistência inicial (CPV - ARI), agregado miúdo (areia grossa) e água, disponibilizados pelo Laboratório de Materiais de Construção Civil (LMCC) da Universidade Federal de Itajubá, campus de Itabira. O material alternativo, objeto deste trabalho, foi o resíduo de construção e demolição, entrando na composição como agregado graúdo, disponibilizado por uma empresa situada na cidade de Belo Horizonte - MG.

Para a confecção dos concretos, foi disposto na betoneira $100 \%$ do agregado graúdo reciclado e $50 \%$ da água (inicialmente para uma relação $\mathrm{a} / \mathrm{c}=0,60$ ), sendo promovida a mistura desses dois componentes. Após essa etapa, colocou-se $100 \%$ do cimento, promovendo a mistura até que fosse atingida a homogeneidade. Por fim, colocou-se $100 \%$ de areia e o restante de água, promovendo a mistura completa dos materiais. Como após a colocação de $100 \%$ da água a consistência adequada não tinha sido alcançada, mais água foi colocada até a relação a/c de 0,80 , sendo essa empregada em todas as 3 dosagens.

Foram realizados os ensaios descritos na sequência para os concretos confeccionados, com o intuito de observar o comportamento das misturas tanto no estado fresco como no estado endurecido. 
- Abatimento do tronco de cone, de acordo com a ABNT NBR NM 67/1998;

- Velocidade de propagação de onda ultrassônica, conforme ABNT NBR 8802/2019;

- Resistência à tração por compressão diametral, de acordo com a ABNT NBR 7222/2011;

- Resistência à compressão simples, seguindo a ABNT NBR 5739/2018.

\section{Resultados e discussões}

\subsection{Caracterização do agregado graúdo reciclado}

\subsubsection{Composição do agregado graúdo reciclado}

A composição dos resíduos de construção e demolição depende da sua origem. Como o ramo da construção civil desenvolve atividades simultâneas no canteiro de obras, os resíduos também são formados por diversos materiais. Esse fato faz com que os resíduos apresentem grande heterogeneidade, de modo que realizar a separação total desse material seria praticamente impossível.

Figura 4 - Composição do resíduo da construção e demolição (RCD)

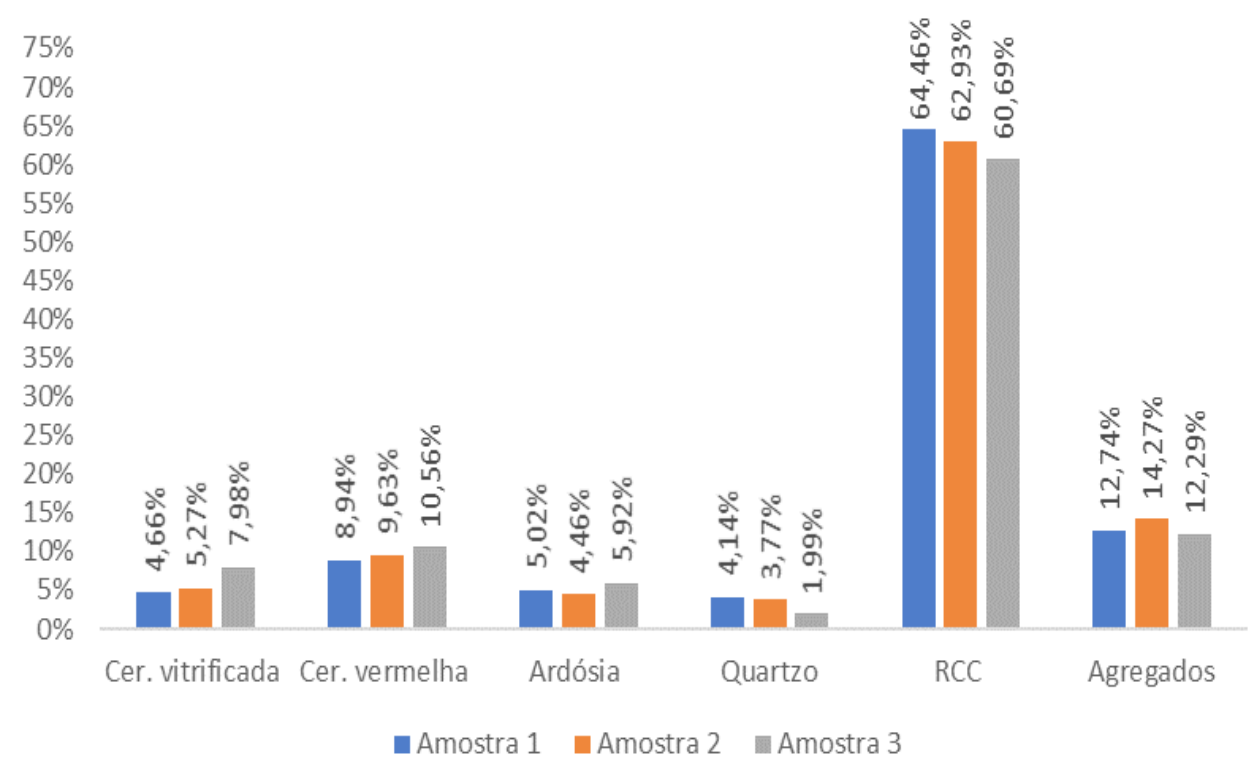

Fonte: Elaborado pelos autores, 2020.

A fim de descobrir a composição do agregado graúdo reciclado pesquisado, como observado na Fig. 4, foi realizada a separação manual do material composto, fazendo o agrupamento de materiais com origem semelhantes. A maior parte do agregado reciclado empregado na pesquisa é composta por resíduos da construção civil (RCC, predominantemente composto por concreto e argamassa), seguido pelos agregados naturais e da cerâmica vermelha, respectivamente.

Calcado (2015) diz que o desempenho do agregado reciclado depende da parcela em que é proveniente. Os agregados da parcela cinza apresentam desempenhos melhores que os agregados da parcela vermelha. Esse fato é explicado pela autora pelas propriedades de autocimentação do cimento desidratado, das partículas de concreto britado e pela superfície mais rugosa, que aumenta a fricção entre partículas, causando redistribuição de tensões.

\subsubsection{Análise granulométrica}

O ensaio de análise granulométrica foi realizado para os três tipos de agregado graúdo reciclado, sendo eles sem tratamento superficial (ST) e com tratamento nas proporções de 1:10 e de 2:10. Tal análise teve por 
objetivo determinar se o tratamento superficial provocou alguma alteração no tamanho dos grãos, devido a um possível aumento de volume, provocado pela formação de uma camada extra, externa ao grão.

Figura 5 - Composição granulométrica dos agregados graúdos reciclados utilizados nas misturas

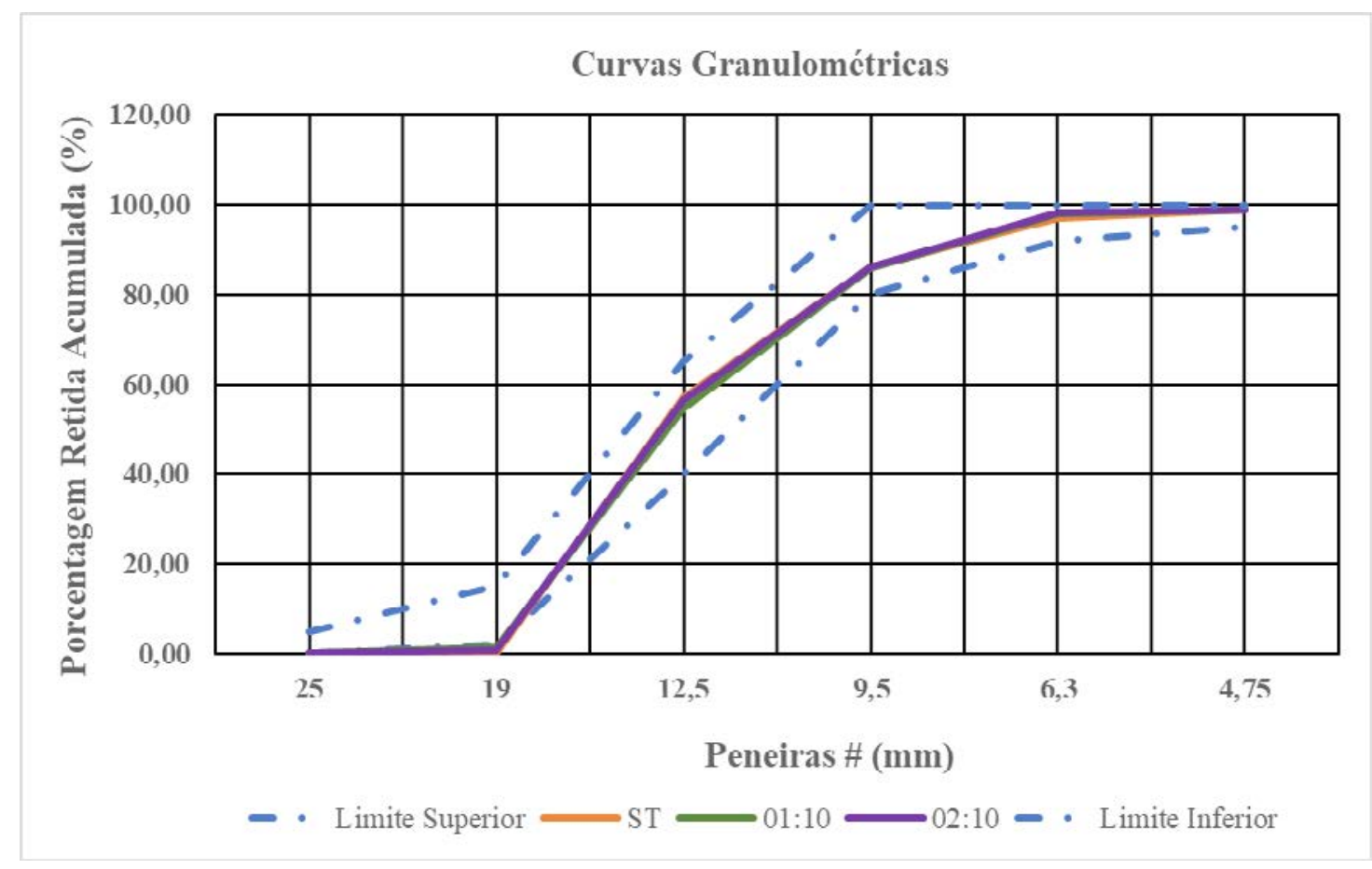

Fonte: Elaborado pelos autores, 2020.

Conforme a Figura 5, as curvas dos três tipos de agregado praticamente se sobrepõem, sinalizando comportamentos idênticos, independentemente do tratamento superficial. Os valores de dimensão máxima característica $\left(D_{\text {máx }}\right)$ e módulo de finura (MF) seguem o comportamento apresentado no gráfico, ficando, respectivamente, $19 \mathrm{~mm}$ e $6,80 \mathrm{~mm}$, além se encaixar na denominação do que seria correspondente a um brita de graduação 1.

\subsubsection{Massa específica, absorção de água e massa unitária}

A massa específica é a razão entre a massa seca da amostra pelo volume do material, levando em consideração os vazios permeáveis. Já para a absorção, avalia a capacidade que um material tem de armazenar umidade no seu interior. A Tabela (1) apresenta os valores médios de três amostragens, encontrados para tais propriedades.

Tabela 1 - Ensaios de caracterização dos agregados graúdos reciclados

\begin{tabular}{l|c|c|c|c}
\hline $\begin{array}{l}\text { Tipo de agregado graúdo } \\
\text { reciclado }\end{array}$ & $\begin{array}{c}\text { Massa específica mé- } \\
\text { dia do agregado seco } \\
\left(\mathrm{g} / \mathrm{cm}^{3}\right)\end{array}$ & $\begin{array}{c}\text { Massa específica média do } \\
\text { agregado na condição saturado } \\
\text { superfície seca }\left(\mathrm{g} / \mathrm{cm}^{3}\right)\end{array}$ & $\begin{array}{c}\text { Absorção } \\
\text { Média }(\%)\end{array}$ & $\begin{array}{c}\text { Massa unitária } \\
\left(\mathrm{g} / \mathrm{cm}^{3}\right)\end{array}$ \\
\hline Sem tratamento (ST) & 2,52 & 2,22 & 9,66 & 1,16 \\
\hline Com tratamento 1:10 & 2,47 & 2,23 & 8,13 & 1,29 \\
\hline Com tratamento 2:10 & 2,49 & 2,23 & 8,57 & 1,21 \\
\hline
\end{tabular}

Fonte: Elaborado pelos autores, 2020. 
Após a realização do tratamento superficial, devido à absorção da pasta de cimento, existia a expectativa de um aumento da massa específica. Entretanto, diferentemente do que aconteceu na pesquisa de Almeida, Santos e Sousa (2018), não foi possível evidenciar o aumento das massas especificas à medida que foi realizado o tratamento superficial. Uma possível explicação pode ser atribuída, também, aos níveis de absorção (bem menores que a referida pesquisa) encontrados no agregado reciclado estudado neste trabalho, em que o aumento de massa, esperado na absorção, não foi suficientemente maior que o aumento de volume do grão proporcionado pela nova camada externa. Sendo assim, para agregados de menores teores de absorção, o tratamento parece não proporcionar o aumento dos valores dessa propriedade.

Para a absorção, a partir da análise dos resultados da Tab (1), é possível perceber uma diminuição considerável na taxa de absorção dos agregados graúdos reciclados com tratamento. Em relação ao agregado com tratamento de 1:10, houve uma melhora de 15,84\% na absorção quando comparado ao agregado graúdo reciclado sem tratamento, enquanto, no agregado com tratamento de $2: 10$, essa melhora foi de $11,28 \%$.

Para a massa unitária foi possível observar o aumento dessa propriedade após a realização do tratamento superficial, conforme apresentado na Tab (1). Levando em consideração que uma camada exterior ao grão provocaria o aumento de sua área superficial (Fig. 6), era de se imaginar um maior índice de vazios no ensaio. Entretanto o aumento da massa do grão parece compensar o maior espaçamento entre os grãos, promovendo a elevação da massa unitária.

Figura 6 - Superfície do grão de agregado reciclado preenchida após o tratamento superficial aplicado

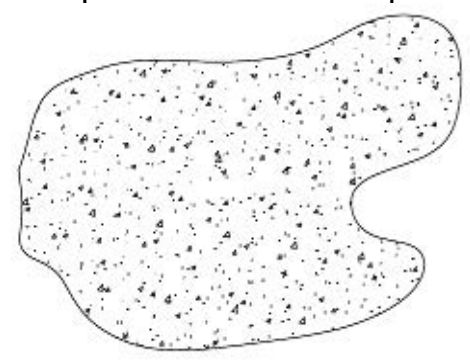

Grão sem tratamento superficial

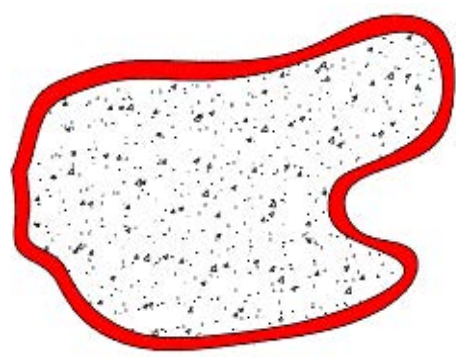

Grão com tratamento superficial

Fonte: Almeida, Santos e Sousa (2018).

Krüger, Pereira e Chinelatto (2017) ressaltam, em seu estudo, a importância de se controlar as características do resíduo, o que permite um aumento do controle das propriedades do concreto com ele confeccionado, afirmando ser tangível a confecção desse compósito com uma boa durabilidade.

\subsection{Estudo das misturas de concreto}

Nesta seção, são apresentados os resultados obtidos, tanto no estado fresco como no estado endurecido, dos concretos confeccionados. Para facilitar a compreensão das misturas estudadas, a sigla CAST foi utilizada para os concretos confeccionados com o agregado reciclado sem tratamento superficial. Para os concretos com agregado graúdo reciclado tratado as siglas foram CAT1 e CAT2, respectivamente, para os agregados que receberam a pasta na proporção 1:10 e 2:10.

No caso do estado fresco das misturas, não foi possível observar nenhuma alteração no valor do abatimento de tronco de cone, ficando todos praticamente no valor zero. Devido ao controle maior da absorção dos agregados graúdos tratados, era de se esperar que as misturas confeccionadas com estes demandassem uma quantidade menor de água para um mesmo abatimento, quando comparados com os agregados reciclados sem tratamento. Entretanto, assim como aconteceu no primeiro teste do tratamento, o que pode explicar o comportamento observado é o fato do agregado mais poroso (sem tratamento) não ter tido tempo de contato suficiente com a água da mistura. Esse contato de forma mais prolongada, permitiria uma maior absorção provocando uma maior demanda de água na mistura para um mesmo abatimento. 
Para o estado endurecido foram realizados três testes, quais sejam: a velocidade de propagação de onda ultrassônica, resistência à tração por compressão diametral e resistência à compressão simples.

\subsubsection{Velocidade de propagação de onda ultrassônica}

A realização deste ensaio teve como objetivo avaliar a diminuição da porosidade proporcionada pelo tratamento superficial do agregado graúdo reciclado. Sendo assim, quanto mais denso o material, maior será a velocidade do pulso nos concretos, podendo ser um indicativo para possíveis melhorias no comportamento mecânico. Conforme observado na Fig. 7, os ensaios foram realizados aos 7 dias e aos 28 dias, assim como para todos os ensaios no estado endurecido.

Figura 7 - Média dos valores da velocidade ultrassônica aos 7 dias e 28 dias

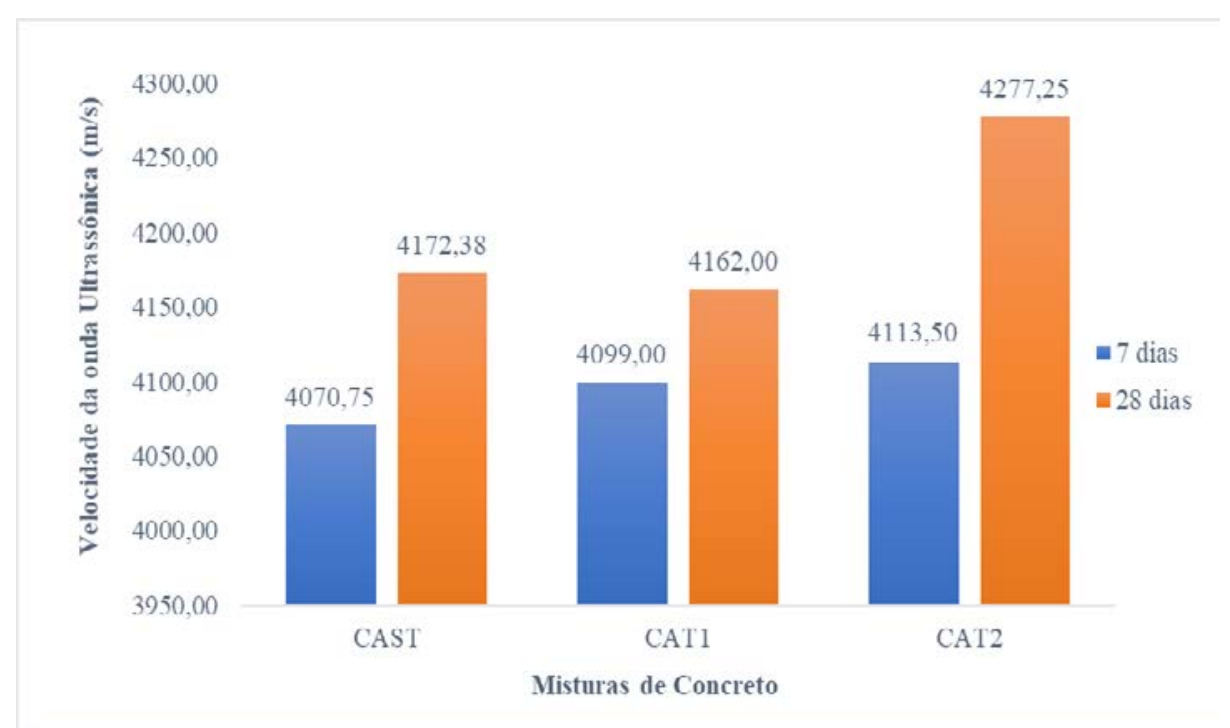

Fonte: Elaborado pelos autores, 2020.

No gráfico, verifica-se uma tendência do aumento do pulso ultrassônico em função do tratamento efetuado. Essa tendência indica que a intenção do tratamento superficial, que era a diminuição da porosidade do grão de agregado reciclado, foi alcançada, proporcionando maiores velocidades do pulso no concreto.

\subsubsection{Resistência à tração por compressão diametral}

Para esse parâmetro, os resultados são apresentados na Fig. 8. Observa-se que, para a idade de 7 dias, os valores de resistência à tração por compressão diametral ficaram praticamente estáveis. Entretanto, quando se avalia os resultados aos 28 dias, nota-se uma diferença considerável nos valores, sendo um aumento de $10,38 \%$ para a mistura CAT1 (tratamento com pasta $1: 10$ ) e de $26,06 \%$ para a mistura CAT2 (tratamento com pasta $2: 10)$. 
Figura 8 - Média dos valores da resistência à tração por compressão diametral aos 7 dias e 28 dias

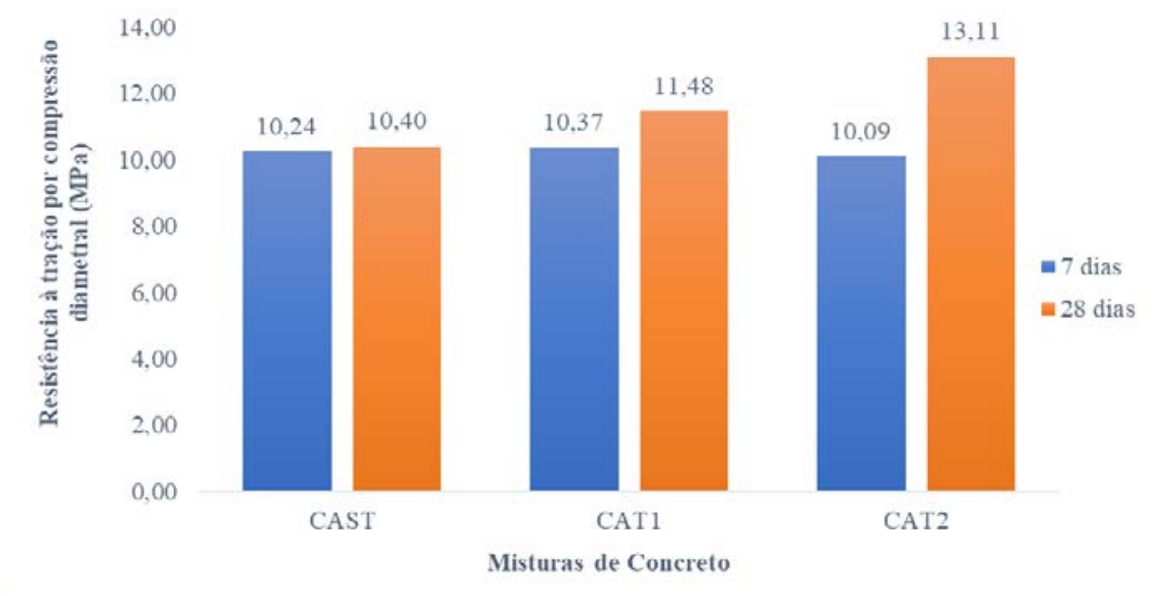

Fonte: Elaborado pelos autores, 2020.

\subsubsection{Resistência à compressão simples}

A Figura 9 apresenta comportamento das misturas à compressão simples, em que os resultados, tanto aos 7 dias como aos 28 dias, apresentaram variações positivas da resistência em função do tratamento efetuado nos agregados graúdos reciclados.

Quando se compara o concreto de referência, fabricado com o agregado reciclado sem tratamento, o rompimento aos 7 dias entre as misturas mostrou um aumento de $14,29 \%$ para o CAT1 e de $25,18 \%$ para o CAT2.

Figura 9 - Média dos valores da resistência à compressão simples aos 7 dias e 28 dias

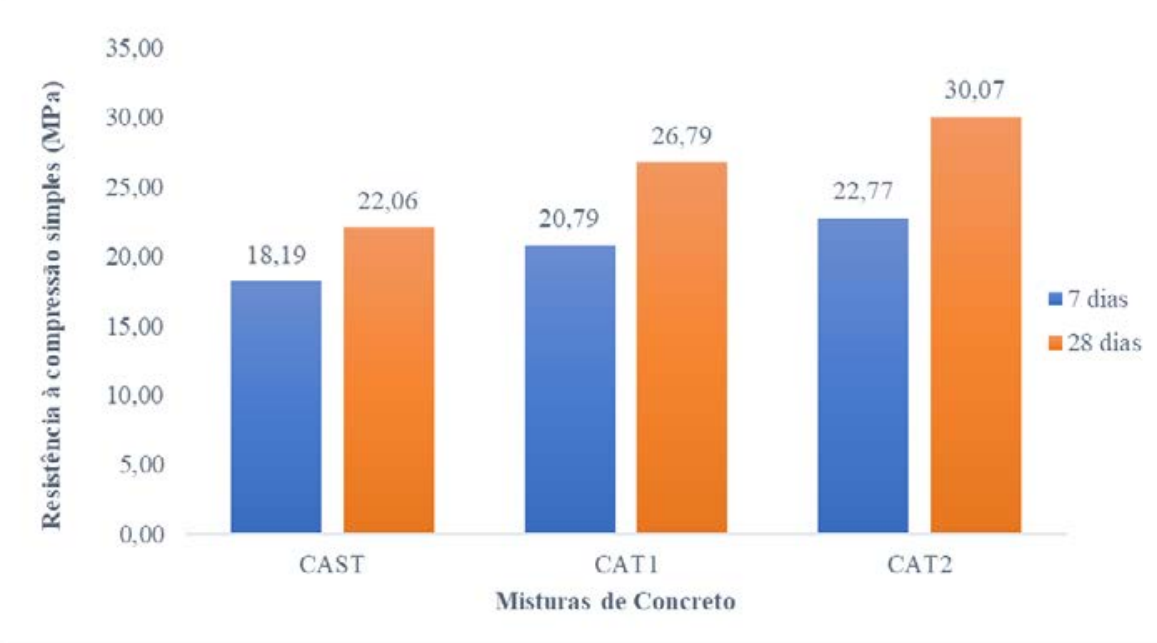

Fonte: Elaborado pelos autores, 2020.

Já para os estudos aos 28 dias, em relação ao concreto de referência, os aumentos foram de $21,44 \%$ para o CAT1 e de $36,31 \%$ para o CAT2. Entre as misturas que possuem o agregado que sofreu o tratamento, as variações foram de $9,52 \%$ e $12,24 \%$, respectivamente, para 7 dias e 28 dias. 
Os resultados demonstram a eficiência do tratamento na melhoria tanto da resistência à tração por compressão diametral do concreto como da sua resistência à compressão simples. Demonstram que o aumento do teor de cimento na pasta utilizada para o tratamento superficial do agregado reciclado também traz melhorias para a mistura.

\section{Conclusões}

Os resultados obtidos a partir dos ensaios realizados neste trabalho comprovaram que o tratamento superficial com pasta de cimento atendeu às expectativas, sinalizando o aprimoramento das características do agregado graúdo reciclado como um material alternativo para a produção de concretos.

O tratamento superficial com pasta de cimento (1:10 e 2:10) proporcionou a formação de uma película externa na superfície dos grãos do agregado graúdo reciclado, diminuindo a capacidade de absorção, característica naturalmente elevada nesse tipo de agregado.

Os resultados do ensaio de absorção de água comprovam o exposto anteriormente, uma vez que os agregados graúdos reciclados com pasta de cimento na proporção de 1:10 obtiveram uma redução de 15,84\% quando comparados com a absorção de água do agregado graúdo reciclado sem tratamento. Já para o agregado com tratamento na proporção de 2:10 essa diminuição foi de 11,28\%.

Ainda com relação à caracterização realizada nos agregados graúdos reciclados após o tratamento, a composição granulométrica, bem como os parâmetros de Dmáx e MF, não foram alterados, mantendo-se as características iniciais do material.

A massa específica média do agregado seco e massa unitária tiveram comportamentos distintos, de modo que a primeira sofreu uma discreta redução e, a segunda, um aumento em relação ao agregado sem tratamento. O processo de absorção da pasta e a formação da camada externa promoveu um aumento da área superficial dos grãos, o que parece ter sido suficiente para o aumento de sua massa, influenciando no aumento da massa unitária. Entretanto o aumento de massa observado parece não ter sido determinante na variação dos valores de massa específica, uma vez que o processo de absorção influencia na determinação desse parâmetro.

As análises dos concretos confeccionados (CAST, CAT1 e CAT2) permitem afirmar que as mudanças nas propriedades foram substanciais no que diz respeito aos comportamentos mecânicos. Tanto o primeiro tratamento (pasta 1:10) como no segundo (pasta 2:10), a absorção da pasta de cimento e a formação da camada externa sinalizam melhorias ocorridas na zona de transição entre pasta e o grão. Tais melhorias podem ter contribuído para os aumentos consideráveis nas resistências à tração por compressão diametral, com um aumento de $26,06 \%$, e na resistência à compressão simples, com um aumento de $36,31 \%$ considerando as variações de CAST para o CAT2.

É de conhecimento do meio técnico que, devido ao maior poder de absorção dos agregados reciclados, sua zona de transição tende a ter uma microrregião de maior relação água/cimento, promovendo uma fragilidade localizada. Com isso, o intuito deste tratamento foi minimizar o comportamento já conhecido de maior fragilidade dessa região. Além da alteração da microrregião entre agregado e pasta, o tratamento superficial pode ter promovido a melhoria da textura superficial dos grãos, provocando o aumento da aderência, principalmente para resíduos de caraterísticas vitrificadas, como as cerâmicas. A textura mencionada pode ser classificada como lisa ou áspera, sendo que essa propriedade resulta da dimensão, dureza e características de porosidade dos materiais que originaram o agregado (GUALBERTO, 2017)

A medida de velocidade de propagação de onda ultrassônica teve o intuito de corroborar a confirmação das alterações provocadas pelo tratamento superficial com pasta de cimento, uma vez que houve um aumento de $2,51 \%$ no CAT2. Uma maior velocidade de onda indica uma maior densificação do meio, provocada, possivelmente, pela absorção de pasta de cimento, tendo por consequência uma diminuição dos vazios.

Diante do exposto, conclui-se que o tratamento superficial com pasta de cimento em agregados reciclados promove a melhoria desse material no que diz respeito à absorção e textura superficial. Tais alterações 
promoveram alterações nos comportamentos mecânicos das misturas confeccionadas com o material tratado, melhorando consideravelmente os valores obtidos. Dessa forma, o tratamento superficial se mostra uma alternativa de melhoria das características dos agregados reciclados, abrindo caminho inclusive para testes com outras matrizes, a fim de avaliar o comportamento.

Isso vai de encontro com Camoleis (2015), que diz que o material reciclado, em substituição ao convencional, deve ser capaz de fabricar um produto com qualidade, estética e produtividade, além de minimizar os impactos da poluição ambiental.

Entretanto é importante ressaltar que os resultados aqui apresentados se limitam às investigações realizadas na presente pesquisa, o que implica em condições específicas e agregados graúdos reciclados de uma fonte única, sendo fundamental a ampliação dos estudos para corroborar o melhor entendimento da técnica proposta.

\section{Referências}

ALMEIDA, Marconi Oliveira de; SANTOS, Fernanda Maria Vieira dos; SOUSA, José Getúlio Gomes de. Tratamento superficial em agregado reciclado, para a produção de blocos de concreto. In: CONGRESSO BRASILEIRO DO CONCRETO, 59., 2018, Bento Gonçalves, Anais, [...]. Bento Gonçalves: IBRACON, 2018.

ASSOCIAÇÃO BRASILEIRA DE NORMAS TÉCNICAS. ABNT NBR 5739: concreto: ensaio de compressão de corpos de prova cilíndricos. Rio de Janeiro: ABNT, 2018.

ASSOCIAÇÃO BRASILEIRA DE NORMAS TÉCNICAS. ABNT NBR 7222: concreto e argamassa: determinação da resistência à tração por compressão diametral de corpos de prova cilíndricos. Rio de Janeiro: ABNT, 2011.

ASSOCIAÇÃO BRASILEIRA DE NORMAS TÉCNICAS. ABNT NBR 8802: concreto endurecido: determinação da velocidade de propagação de onda ultrassônica. Rio de Janeiro: ABNT, 2019.

ASSOCIAÇÃO BRASILEIRA DE NORMAS TÉCNICAS. ABNT NBR NM 45: agregados: determinação da massa unitária e volume de vazios. Rio de Janeiro: ABNT, 2006.

ASSOCIAÇÃO BRASILEIRA DE NORMAS TÉCNICAS. ABNT NBR NM 53: agregado graúdo: determinação da massa específica, massa específica aparente e absorção de água. Rio de Janeiro: ABNT, 2002.

ASSOCIAÇÃO BRASILEIRA DE NORMAS TÉCNICAS. ABNT NBR NM 67: concreto: determinação da consistência pelo abatimento do tronco de cone. Rio de Janeiro: ABNT,1998.

ASSOCIAÇÃO BRASILEIRA DE NORMAS TÉCNICAS. ABNT NBR NM 248: agregados: determinação da composição granulométrica. Rio de Janeiro: ABNT, 2001.

ATHAYDE, Priscila Botelho. Influência do uso de agregados reciclados nas propriedades dos concretos. 2018. 59 f. Monografia (Especialização em Produção e Gestão do Ambiente Construído) Universidade Federal de Minas Gerais, Belo Horizonte, 2018.

BRASILEIRO, Luzana Leite. Utilização de agregados reciclados provenientes de RCD em substituição ao agregado natural no concreto asfáltico. 2013. 118f. Dissertação (Mestrado em Ciências dos Materiais) -Universidade Federal do Piauí, Teresina, 2013.

CALCADO, Gabrielle Christina da Silva. Influência da adição de agregados reciclados de resíduos de construção e demolição no desempenho de argamassas de cimento Portland. 2015. $101 \mathrm{f}$. Trabalho de Conclusão de Curso (Bacharelado em Engenharia Civil) - Escola Politécnica da Universidade Federal do Rio de Janeiro, Rio de Janeiro, 2015. 
CAMOLEIS, Luis Carlos; BUENO, José Roberto P.; SILVA, João Henrique do Nascimento e. A empregabilidade dos resíduos de construção civil e demolição (RCD): benefícios ambientais. 2015. Araras: Centro Universitário de Araras, 2015.

CARRIJO, Priscila Meireles. Análise da influência da massa específica de agregados graúdos provenientes de resíduos de construção e demolição no desempenho mecânico do concreto. 2005. 146 f. Dissertação (Mestrado em Engenharia Civil) - Universidade de São Paulo, São Paulo, 2005.

COSTA, N. da; COSTA JÚNIOR, N. da; LUNA, M.; SELIG, P.; ROCHA, J. Planejamento de programas de reciclagem de resíduos de construção e demolição no Brasil: uma análise multivariada. Engenharia Sanitária Ambiental, Florianópolis, v. 12, n. 4, p. 456-467, 2007.

DAMINELI, Luís Bruno. Estudos de métodos para caracterização de propriedades físicas de agregados graúdos de resíduos sólidos e demolição reciclado. Orientador: Vanderley Moacyr John. 2007. 125f. Dissertação (Mestrado em Engenharia) - Departamento de Engenharia de Construção Civil, Escola Politécnica da Universidade de São Paulo, São Paulo, 2007.

GONÇALVES, Rodrigo Dantas Cassilo. Agregados reciclados de resíduos de concreto: um novo material para dosagens estruturais. 148f. Dissertação (Mestrado em Engenharia de Estruturas) Departamento de Engenharia Civil, Escola de Engenharia de São Carlos, São Carlos, 2001.

GUALBERTO, Alane Bessa. Avaliação do uso de resíduos de construção civil reciclados como agregados do concreto em um pátio de compostagem. 2017. 124 f. Dissertação (Mestrado em Engenharia Civil) -Universidade Federal de Viçosa, Viçosa, 2017.

KRÜGER, Patrícia; PEREIRA, Eduardo e CHINELATTO, Adriana S. A. Influência do agregado reciclado na durabilidade do concreto: uma revisão da bibliografia. Revista técnico científica do CREA-PR, Paraná, p. 1-18, 2017. Edição especial.

LEITE, M. B. Avaliações de propriedades mecânicas de concretos produzidos com agregados reciclados de resíduos de construção e demolição. Orientador: Denise Carpena Coitinho Dal Molin. 2001. 222. Tese (Doutorado em Engenharia Civil) - Universidade Federal do Rio Grande do Sul, 270 f. 2001.

LIMA, J. A. R. Proposição de diretrizes para produção e normalização de resíduo de construção reciclado e de suas aplicações em argamassas e concretos. Orientador: Laércio Ferreira e Silva. 1999. 222f. Dissertação (Mestrado) - Escola de Engenharia de São Carlos, Universidade de São Paulo, 1999.

MOTTA, Rosangela dos Santos. Estudo laboratorial de agregado reciclado de resíduo de sólido da construção civil para aplicação em pavimentação de baixo volume de tráfego. Orientador: Liedi Légi Bariani Bernucci. 2005. 161f. Dissertação (Mestrado em Engenharia de Transportes) - Escola Politécnica, Universidade de São Paulo, São Paulo, 2005

SANTOS, Winnie Franco. Tratamento superficial dos agregados reciclados de RCD com hidrofungantes. Orientador: Sérgio Cirelli Ângulo. 2016. 166 f. Dissertação (Mestrado em Ciências) Universidade de São Paulo, São Paulo, 2016. 
Sobre os autores

\section{Marina Guerra}

Engenheira da Mobilidade pela Universidade Federal de Itajubá (Unifei) - Campus Itabira (MG) e graduanda em Engenharia Civil - Fundação Comunitária de Ensino Superior de Itabira (FUNCESI).

\section{Marconi Oliveira de Almeida}

Mestrado na área de construção civil pela Universidade Federal de Santa Catarina (UFSC - 1999). Possui graduação em Engenharia Civil pela Universidade Vale do Rio Doce (Univale - 1996). Trabalhou durante 10 anos na Universidade Federal do Vale do São Francisco (UNIVASF - Juazeiro/BA), tanto na sua implementação como na consolidação do curso de Engenharia Civil. Atualmente é professor Adjunto IV Mestre da Universidade Federal de Itajubá - Campus Itabira/MG, estando lotado no Instituto de Engenharias Integradas (IEI), lecionando no curso de Engenharia da Mobilidade e exercendo o posto de coordenador do Laboratório de Pavimentação (LABPAV). Tem experiência na área de Engenharia Civil e Engenharia da Mobilidade, com ênfase em Materiais e Componentes da Construção, atuando principalmente nos seguintes temas: reciclagem, recuperação, concreto, patologia, concreto com fibras, pavimentação e manutenção de rodovias e ferrovias.

\section{Sérgio Pacífico Soncim}

Doutorado em Ciências - Infraestrutura de Transportes- pela Universidade de São Paulo (2011) e mestrado em Engenharia de Transportes pelo Instituto Militar de Engenharia (2002). Possui graduação em Engenharia Civil pela Universidade Federal de Ouro Preto (1998), e lecionou no curso de Engenharia Civil da Universidade Federal da Bahia entre 2004 e 2013. Atualmente é Professor Associado da Universidade Federal de Itajubá. Tem experiência na área de Infraestrutura de Transportes, com ênfase em Pavimentação, atuando principalmente nos seguintes temas: pavimentos asfálticos e sistemas de gerência.

\section{Carlos Augusto Souza Oliveira}

Doutorado (2007) na área de Ciência e Engenharia de Materiais no Programa de Pós-Graduação em Engenharia Metalúrgica, Materiais e de Minas da Universidade Federal de Minas Gerais mestrado (2004). Possui graduação em Engenharia Civil pela Universidade Federal de Minas Gerais (2000), e atualmente é Professor Associado da Universidade Federal de Itajubá, lecionando no Programa de Mestrado Profissional em Engenharia Produção e no Curso de Graduação em Engenharia da Mobilidade. Tem experiência na área de Engenharia Civil, com ênfase em Materiais e Métodos Construtivos, atuando principalmente com os seguintes temas: aproveitamento de resíduos, desenvolvimento de produtos para a construção civil, estudos de concretos especiais, durabilidade de materiais e manifestações patológicas em edificações.

Recebido em: 06.05.2020

Aceito em: 18.05 .2020 